\title{
Biological activity, molecular docking, and ADME predictions of amphibine analogues of Ziziphus spina-christi towards SARS-CoV-2 M Mro $^{\text {pro }}$
}

\author{
Taufik Muhammad Fakih ${ }^{1 *}$, Dwi Syah Fitra Ramadhan ${ }^{2}$, Fitrianti Darusman ${ }^{1}$ \\ ${ }^{1}$ Department of Pharmacy, Faculty of Mathematics and Natural Sciences, Universitas Islam Bandung \\ Jl. Rangga Gading No. 8 Bandung, West Java, Indonesia. 40116 \\ *Email: taufikmuhammadf@gmail.com \\ ${ }^{2}$ Department of Pharmacy, Universitas Mandala Waluya \\ J1. Jend. AH. Nasution Blok G-37 Kendari, Southeast Sulawesi, Indonesia. 93561
}

\begin{abstract}
The main protease of the SARS-CoV-2 virus, SARS-CoV-2 $\mathrm{M}^{\text {pro }}$, can be discovered as a promising target to treat the COVID-19 pandemic. The peptide-based inhibitors may present better options than small molecules to inhibit SARS-CoV-2 M $\mathrm{M}^{\text {pro }}$. Ziziphus spina-christi species reported have a peptidebased of alkaloids group, i.e., amphibine whose analogues can be identified the potential as an inhibitor of

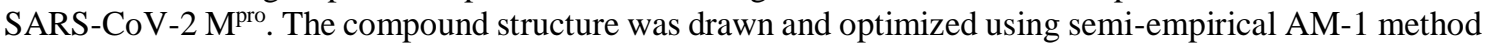
using Quantum ESPRESSO v.6.6, while the biological activity using PASS. Prediction server and molecular docking simulation using MGLTools 1.5.6 with AutoDock 4.2 were performed. Afterward, the ADME profiles were predicted using the SWISS-ADME server. PASS server was predicting amphibine B$\mathrm{F}$ and $\mathrm{H}$ showed potency both as antiviral and as a protease inhibitor. The molecular docking simulation of amphibine analogues showed lower binding energy than the native ligand. The binding energy of the native ligand was $-7.69 \mathrm{Kcal} / \mathrm{mol}$ compared to the lowest binding energy of amphibine analogues was -10.10 $\mathrm{Kcal} / \mathrm{mol}$ (amphibine-F). The ADME prediction showed that amphibine-F has the best bioavailability as an oral drug, amphibine-B, C, and D have good bioavailability, and amphibian-E and $\mathrm{H}$ have poor bioavailability. Concluded, amphibine B-F and H of amphibine analogues showed potency as COVID-19 treatment targeting SARS-CoV-2 Mpro.
\end{abstract}

Keywords: Christ's thorn jujube; COVID-19 therapy; in silico study; SARS-CoV-2 Mpro; semi-empirical AM-1

Article History: Received 25 April 2021; Received in revised form 6 May 2021; Accepted 30 May 2021; Available online 30 June 2021

How to Cite This Article: Fakih TM, Dwi Syah Fitra Ramadhan DSF, Darusman F. 2021. Biological activity, molecular docking, and ADME predictions of amphibine analogues of Ziziphus spina-christi towards SARS-CoV-2 $\mathrm{M}^{\text {pro }}$. Biogenesis: Jurnal Ilmiah Biologi. vol 9(1): 109-117. doi: https://doi.org/10.24252/bio.v9i1.21335.

\section{INTRODUCTION}

The Coronavirus disease 2019 has spread worldwide and still become a health problem that needs attention (Thompson, 2020; Zhu et al., 2020). Released on March 2021 in the present situational report from WHO, 3.8 million COVID-19 new cases, and 64000 recent deaths were reported globally. (WHO, 2021). Clinically, COVID-19 can lead to severe respiratory complications and death with fever and respiratory symptoms (Calcagno et al., 2020).

SARS-CoV-2 main protease $\left(\mathrm{M}^{\mathrm{pro}}\right)$, which can be crystallized along with its inhibitors, was one of the most promising targets for COVID19 drug discovery (Jin et al., 2020; Khaerunnisa et al., 2020; Mirza \& Froeyen, 2020; Reiner et al., 2020), and become the key enzyme of viral polyprotein maturation, replication and transcription cycle (Dai et al., 2020; Fu et al., 2020; Goyal \& Goyal, 2020). SARS-CoV M ${ }^{\text {pro }}$ is resistant to peptide-like anti-HIV-1 drugs, hence SARS-CoV and SARS-CoV-2 SARSCoV-2 is closely related to, but distinct from the SARS-CoV branch on phylogenetic relationship (Choudhury \& Mukherjee, 2020; Dong et al., 2020). Both virus rely on main protease associated with N3 inhibition (Griffin, 2020). Small compounds may not be as effective as peptide-based inhibitors in the treatment of COVID-19 (Gentile et al., 2020; Han \& Král, 2020; Maiti, 2020; Murdocca et al., 2021).

The natural product compounds based on peptide-like from medicinal plants become our orientation research. Hence, they have not been explored intensively in drug discovery, especially those that can inhibit COVID-19 (Dias et al., 2012; Harvey et al., 2015; Benarba \& Pandiella, 2020; Lakshmi et al., 2020). Z. spina-christi as important medicinal plant (El Maaiden et al., 2019) is a deciduous tree that 
generally comes from warm and subtropical climates, such as North Africa, South Europe, Mediterranean, tropical America, South and East of Asia, and others, including Indonesia (Kwape et al., 2013; Moossavi et al., 2017). There are many names for Z. spina-christi, known as Christ's thorn jujube, belongs to the Rhamnaceae family with large shade tree (Baghazadeh-Daryaii et al., 2017; Gorai et al., 2019).

The previous studies have reported that $Z$. spina-christi provided a variety of pharmacological activities, including antibacterial, antifungal, antioxidant, antihyperglycemic, and anti-diabetic (Kalayou et al., 2012; Ads et al., 2017; Al-Ghamdi et al., 2017; Alotibi et al., 2020). According to our previous studies, the main phytochemicals were discovered in this plant include alkaloids, flavonoids, and saponins (Darusman \& Fakih, 2021). Tuenter et al. (2017) and Sakna et al. (2019) stated cyclopeptide alkaloids can be found in their stem-bark.

To date, the need for a vaccine and antiviral development is increasing, especially those targeting SARS-CoV-2 $\mathrm{M}^{\text {pro }}$. Computational approaches were demonstrated to predict the affinity and molecular behavior of amphibine analogues from the plant compound. We are interested in investigating the potency of the amphibine analogues (cyclopeptide alkaloids) from Z. spina-christi, as a promising future treatment for COVID-19 targeting SARS-CoV$2 \mathrm{M}^{\text {pro }}$.

\section{MATERIALS AND METHODS}

Ligand preparation. The ligands chosen for this research were peptide alkaloids, amphibine analogues in Ziziphus spina-christi, i.e., amphibine A-H compounds. The 3D ligand structures were drawn and optimized based semi-empirical AM-1 method using Quantum ESPRESSO v.6.6 (Giannozzi et al., 2020). The research protocols were following our previous studies (Fakih et al., 2021).

Receptor preparation. The 3D structure of SARS-CoV-2 $\mathrm{M}^{\text {pro }}$ was obtained from the Protein Data Bank (PDB) (http://www.rcsb.org/pdb/). The high resolution of the SARS-CoV-2 $\mathrm{M}^{\text {pro }}$ receptor
(2.15 ̊) with PDB ID: 6WTT was chosen (Ma et al., 2020). The receptor was complexed with boceprevir, an HCV protease inhibitor as a native ligand. Afterward, all the unique ligands and water molecules were removed from the receptor, and then the polar hydrogen and a charge (Kollman charge) were added to the protein structure. The protein preparation procedures were executed using MGLTools 1.5.6 with AutoDock 4.2 (Tanbin et al., 2021).

Biological activity prediction. The biological activity spectra of amphibine analogues were assessed using the PASS prediction web server (http://www.way2drug.com/PASSOnline/predi ct.php) (Lagunin et al., 2000). The predicted spectrum was estimated as probable activity $(\mathrm{Pa})$ and probable inactivity $(\mathrm{Pi})$, based on structure-activity relationship analysis of the training set containing more than 205000 compounds exhibiting more than 3750 kinds of biological activities. Pa and Pi values vary from 0.000 to 1.000 since they are probabilities. The PASS prediction was interpreted and used flexibly, according to Anzali et al. (2001).

Molecular docking simulation. The molecular docking simulation method was validated using RMSD calculation by redocked the crystallographic native ligand. The best conformation of docked native ligand was taken and superimposed with the native ligand before docked, and the Root-Mean-Square Deviation (RMSD) was calculated. The acceptable RMSD value must be less than 2.0 $\AA$ (Bell \& Zhang, 2019). Afterward, the amphibine analogues were docked into the binding pocket of the SARS-CoV-2 $\mathrm{M}^{\text {pro }}$. The grid box was set with coordinates 5.499, 27.197, and -11.76 (x, y, and $\mathrm{z}$, respectively), and the dimensions of the grid box were 64, 60, and $60(\mathrm{x}, \mathrm{y}$, and $\mathrm{z})$, and numbers of GA run was 100 (Atilgan \& Hu, 2011).

ADME prediction. We analyzed the adsorption, distribution, metabolism, and excretion (ADME) profile of the amphibine analogues, which could be used as a drug. We used the SWISS-ADME web server to predict the ADME profile (https://www.swissadme.ch), which allows the user to draw or input their molecules data and 
provides the parameters such as lipophilicity, water-solubility, pharmacokinetics, druglikeness rules, and medicinal chemistry (Mahanthesh et al., 2020).

\section{RESULTS AND DISCUSSION}

Biological activity prediction. The PASS prediction web server's biological activity was carried out on amphibine analogues (A-H) compounds to see the level as a COVID-19 main protease inhibitor (Table 1).

The PASS web server predicts various biological activities of Amphibine analogues, but the focus of the research here is on the prediction of antiviral and protease inhibitor agents. All amphibine A-H were predicted to have an activity as antiviral agents. As protease enzyme inhibitors, amphibine B, C, D, E, F, and $\mathrm{H}$ showed activity, whereas amphibine $\mathrm{A}$ and $\mathrm{G}$ showed no activity. Amphibine-C showed the best-predicted activity spectrum of 0.298 for antiviral activity and 0.151 for protease inhibitor activity. Overall, in line with Abdelli et al. (2021) and Shah et al. (2021), amphibine $\mathrm{B}, \mathrm{C}, \mathrm{D}, \mathrm{E}, \mathrm{F}$, and $\mathrm{H}$ compounds showed potency both as antiviral activity and protease inhibitors.
Table 1. In silico prediction of activity spectra for substances (PASS) results.

\begin{tabular}{|c|c|c|c|}
\hline Compounds & $\begin{array}{l}\text { Activities } \\
\text { prediction }\end{array}$ & $\mathrm{Pa}$ & $\mathrm{Pi}$ \\
\hline \multirow[b]{2}{*}{ Amphibine-A } & Antiviral & 0.162 & \multirow{2}{*}{$\begin{array}{l}0.145 \\
-\end{array}$} \\
\hline & $\begin{array}{l}\text { Protease } \\
\text { Inhibitor }\end{array}$ & - & \\
\hline \multirow[b]{2}{*}{ Amphibine-B } & Antiviral & 0.278 & \multirow{2}{*}{$\begin{array}{l}0.005 \\
0.057\end{array}$} \\
\hline & $\begin{array}{l}\text { Protease } \\
\text { inhibitor }\end{array}$ & 0.136 & \\
\hline \multirow[b]{2}{*}{ Amphibine-C } & Antiviral & 0.298 & \multirow{2}{*}{$\begin{array}{l}0.037 \\
0.050\end{array}$} \\
\hline & $\begin{array}{l}\text { Protease } \\
\text { Inhibitor }\end{array}$ & 0.151 & \\
\hline \multirow[b]{2}{*}{ Amphibine-D } & Antiviral & 0.278 & \multirow{2}{*}{$\begin{array}{l}0.045 \\
0.075\end{array}$} \\
\hline & $\begin{array}{l}\text { Protease } \\
\text { Inhibitor }\end{array}$ & 0.112 & \\
\hline \multirow[b]{2}{*}{ Amphibine-E } & Antiviral & 0.200 & \multirow{2}{*}{$\begin{array}{l}0.096 \\
0.085\end{array}$} \\
\hline & $\begin{array}{l}\text { Protease } \\
\text { Inhibitor }\end{array}$ & 0.102 & \\
\hline \multirow[b]{2}{*}{ Amphibine-F } & Antiviral & 0.290 & \multirow{2}{*}{$\begin{array}{l}0.040 \\
0.090\end{array}$} \\
\hline & $\begin{array}{l}\text { Protease } \\
\text { Inhibitor }\end{array}$ & 0.098 & \\
\hline \multirow[b]{2}{*}{ Amphibine-G } & Antiviral & 0.195 & \multirow{2}{*}{$\begin{array}{l}0.015 \\
-\end{array}$} \\
\hline & $\begin{array}{l}\text { Protease } \\
\text { Inhibitor }\end{array}$ & - & \\
\hline \multirow[b]{2}{*}{ Amphibine-H } & Antiviral & 0.263 & \multirow{2}{*}{$\begin{array}{l}0.052 \\
0.070\end{array}$} \\
\hline & $\begin{array}{l}\text { Protease } \\
\text { Inhibitor }\end{array}$ & 0.118 & \\
\hline
\end{tabular}

Amphibine-C

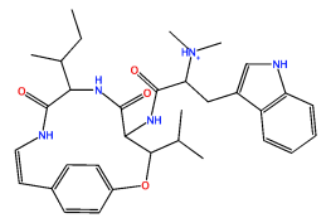

Amphibine-A

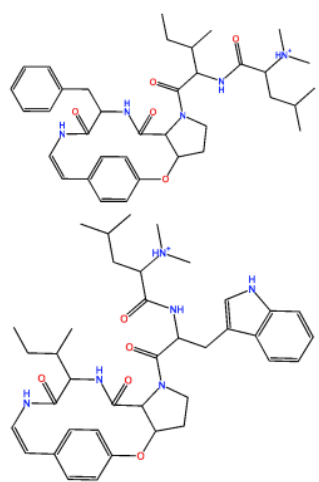

Amphibine-E

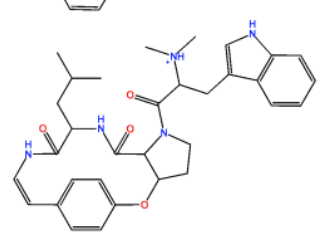

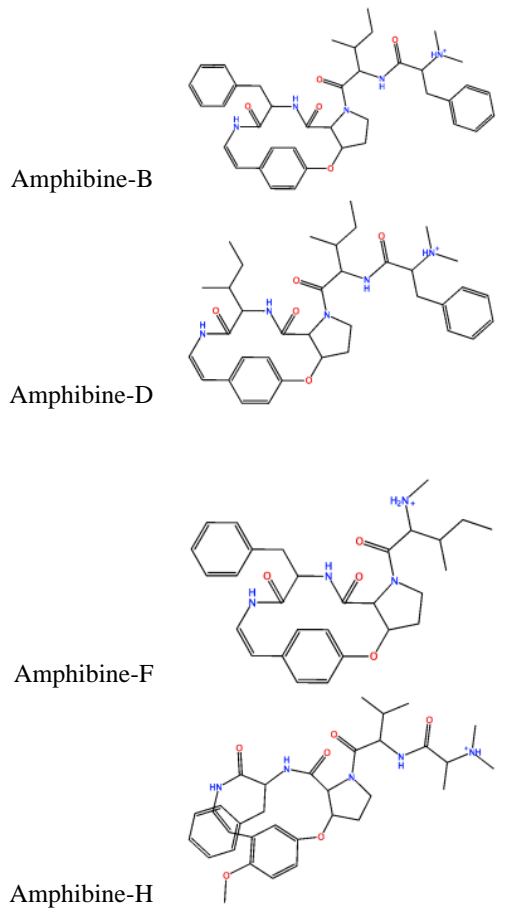

Fig. 1. Chemical structure of amphibine A-H. 
Molecular docking simulation. Molecular docking simulation study was performed on the crystal structure of SARS $\mathrm{CoV}-2 \mathrm{M}^{\text {pro }}$ to assess the binding affinity potency of amphibine analogues (amphibine B, $\mathrm{C}, \mathrm{D}, \mathrm{E}, \mathrm{F}$, and $\mathrm{H}$ ) that were previously predicted using the PASS website. The docking methods were validated to see the strength of binding mode prediction through re-docking the native ligand. The RMSD value of the native ligand obtained was $1.30 \AA$, which shows that the molecular docking method was valid. The amphibine analogues were then docked into the binding site of the crystal structure of SARS-CoV-2 $\mathrm{M}^{\text {pro }}$. All of the docking results of amphibine A-H showed high binding energy and $\mathrm{Ki}$ compared to the native ligand (Table 2). The negative sign or the lowest binding energy is considered to be a stable binding affinity to the receptor. The binding energy of the native ligand was -7.69 $\mathrm{Kcal} / \mathrm{mol}$. The amphibine analogues binding energy sort by lowest to highest were -10.10 $\mathrm{Kcal} / \mathrm{mol}$ (amphibine-F), $-9.22 \mathrm{Kcal} / \mathrm{mol}$ (amphibine-E), $-9.07 \mathrm{Kcal} / \mathrm{mol}$ (amphibine-B), -8.83 Kcal/mol (amphibine-H), -8.71 $\mathrm{Kcal} / \mathrm{mol}$ (amphibine-D), and $-8.07 \mathrm{Kcal} / \mathrm{mol}$ (amphibine-C).

Table 2. The binding energy and $\mathrm{Ki}$ of the amphibine of Ziziphus spina-christi to the SARS-CoV-2 M ${ }^{\text {pro }}$ receptor.

\begin{tabular}{llll}
\hline No & Compounds & $\begin{array}{l}\text { Binding energy } \\
\text { (Kcal/mol) }\end{array}$ & Ki (nM) \\
\hline 1 & Native ligand & -7.69 & 2300 \\
2 & Amphibine-B & -9.07 & 224.22 \\
3 & Amphibine-C & -8.07 & 1220 \\
4 & Amphibine-D & -8.71 & 411.85 \\
5 & Amphibine-E & -9.22 & 173.95 \\
6 & Amphibine-F & -10.10 & 39.51 \\
7 & Amphibine-H & -8.83 & 335.11 \\
\hline
\end{tabular}

Molecular interactions. The ligandreceptor interactions of the best binding mode of the Amphibine analogues were analyzed and compared to reference native ligand binding mode toward the SARS-CoV-2 $\mathrm{M}^{\text {pro }}$. The tabulation data of the amino acid interactions were provided in Table 3, and the 2D interaction was provided in Fig. 2. Native ligand in its interactions, form hydrogen bonds with amino acids Glu166, His164, Phe140, Gln189, Cys145, and other types of interaction with residue Cys145 (unfavorable bump), His163 (unfavorable acceptor-acceptor), Pro168 (Pi-alkyl), Met165 (alkyl), His41 (alkyl \& carbon-hydrogen bond), and His172 (carbonhydrogen bond). Amphibine-B showed hydrogen bond interaction with three amino acids, i.e., Glu166, Ser144, Asn142, and other types of interaction with amino acids Glu166 (Pi-Anion), Pro168 (Pi-sigma), His41 (alkyl), Cys145 (Pi-alkyl), and His163 (unfavorable acceptor-acceptor). Amphibine-C showed hydrogen bond interaction with two amino acids, including Glu166 and Gln189. Other types of interaction with amino acids Gln189 (carbon-hydrogen bond), Glu166 (carbonhydrogen bond), Pro168 (Pi-sigma), Met49 (Pisulfur), His41 (Pi-alkyl \& Pi-pi stacked), Leu167 (Pi-alkyl), Leu141 (alkyl). AmphibineD showed hydrogen bond interaction with one amino acid (Glu166) and other types of interaction with amino acids Met165 (alkyl \& Pi-sulfur), His41 (carbon-hydrogen bond), Thr24 (carbon-hydrogen bond), Cys145 (Pihydrogen bond). Amphibine-E showed hydrogen bond interaction with three amino acids, including Glu166, Gln192, and Gln189, and other types of interaction with amino acids Ala191 (Pi-alkyl), Pro168 (Pi-alkyl), His41 (Pisigma). Amphibine-F showed hydrogen bond interaction with three amino acids, including His41, Glu166, and Gln189, and other types of interaction with amino acids His41 (Pi-sigma \& unfavorable acceptor-Acceptor), Glu166 (Pianion), Gln189 (carbon-hydrogen bond), Arg188 (carbon-hydrogen bond), Met165 (alkyl). Amphibine-H showed hydrogen bond interaction with three amino acids, including Glu166, Gln192, and Thr190, and other types of interaction with amino acids Ala191 (Pialkyl), Met165 (alkyl), Glu166 (carbonhydrogen bond), and Phe140 (carbon-hydrogen bond). 
Table 3. Tabulation data of amino acid interactions of reference ligand (native ligand) compared to cyclopeptide alkaloids in SARS-CoV-2 Mro.

\begin{tabular}{|c|c|c|c|}
\hline Ligands & & H-bond interactions & Other type of interactions \\
\hline $\begin{array}{l}\text { Reference } \\
\text { (boceprevir) }\end{array}$ & ligand & $\begin{array}{l}\text { Glu166, His164, Phe140, Gln189, } \\
\text { Cys145 }\end{array}$ & $\begin{array}{l}\text { Cys145k, His163l, Pro168d, Met165c, } \\
\text { His41c,f, His172f }\end{array}$ \\
\hline Amphibine-B & & Glu166, Ser144, Asn142 & $\begin{array}{l}\text { Glu166a, Pro168b, His41c, Cys145d, } \\
\text { His163e }\end{array}$ \\
\hline Amphibine-C & & Glu166, Gln189 & $\begin{array}{l}\text { Gln189f, Glu166f, Pro168b, Met49g, } \\
\text { His41d,h, Leu167d, Leu141c }\end{array}$ \\
\hline Amphibine-D & & Glu166 & Met165c,g, His41f, Thr24f, Cys145i \\
\hline Amphibine-E & & Glu166, Gln192, Gln189 & Ala191d, Pro168d, His41b \\
\hline Amphibine-F & & His41, Glu166, Gln 189 & $\begin{array}{l}\text { His41b,e, Glu166j, Gln189f, Arg188f, } \\
\text { Met165c }\end{array}$ \\
\hline Amphibine-H & & Glu166, Gln192, Thr190 & Ala191d, Met165c, Glu166f, Phe140f \\
\hline
\end{tabular}

Notes: $\mathrm{a}=$ Pi-anion; $\mathrm{b}=$ Pi-sigma; $\mathrm{c}=$ alkyl; $\mathrm{d}=$ Pi-alkyl; $\mathrm{e}=$ unfavorable acceptor-acceptor; $\mathrm{f}=$ carbon-hydrogen bond; $\mathrm{g}=\mathrm{Pi}-\mathrm{sulphur}$; $\mathrm{h}=\mathrm{Pi}$-pi stacked; $\mathrm{i}=$ Pi-hydrogen bond; $\mathrm{j}=\mathrm{Pi}$-anion; $\mathrm{k}=$ unfavorable bump; $\mathrm{l}=$ unfavorable acceptor-acceptor.

The hydrogen bond is an attractive interaction between a hydrogen atom from fragment $\mathrm{X}-\mathrm{H}$, and enhance receptor-ligand interactions (Arunan et al., 2011; Chen et al., 2016). Native ligands binding mode still showed the highest intensity of hydrogen bonding (five hydrogen bonds), followed by amphibine-B, amphibine-E, amphibine-F, and amphibine-H with three numbers of the hydrogen bond, then amphibine-C (two hydrogen bond), and Amphibine-D (1 hydrogen bond). The similarity of amino acid interaction types between the native ligand as a reference and amphibine analogues showed in the amphibine-B, amphibine-C, amphibine-D, and amphibine-H provided one type of hydrogen bond interaction similar (Glu166). The amphibine-E and amphibine-F compounds showed two similar hydrogen bond interactions to the reference ligand (Glu166 \& Gln189). The other interactions, i.e., Pi-sigma, Pi-alkyl, and Pi-sulphur, mostly involve charge transfer assisting in intercalating the drug at the receptor-binding site. The highest number of amino acid interactions that form those other interactions were dominated by amphibine-C, amphibine- $\mathrm{B}$, amphibine- $\mathrm{F}$, amphibine- $\mathrm{H}$, amphibine-E, and amphibine-D, respectively.

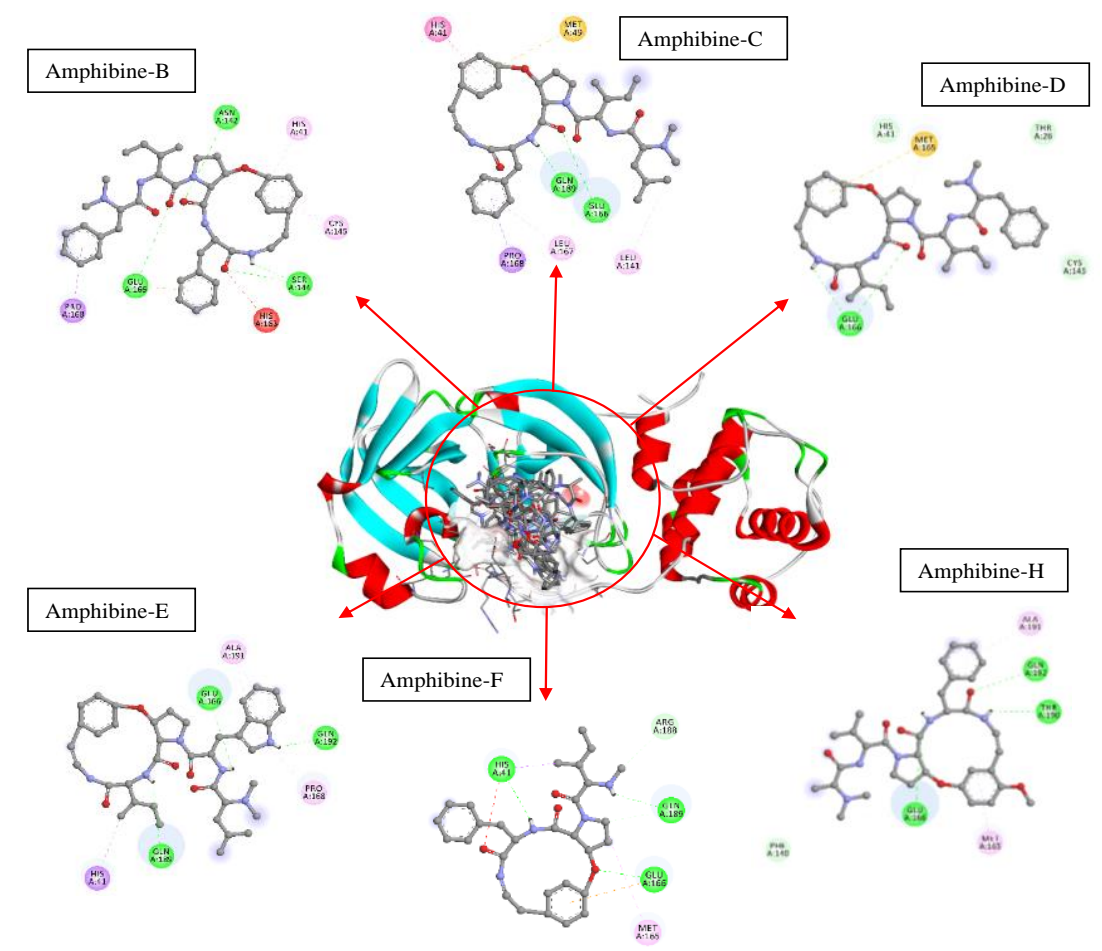

Fig. 2. Molecular interaction of native ligand and amphibine B, C, D, E, F, and H 
ADME prediction. The amphibine analogues predicted before $(\mathrm{B}, \mathrm{C}, \mathrm{D}, \mathrm{E}, \mathrm{F}$, and $\mathrm{H})$ have been analyzed by ADME profile using SWISS-ADME (Fig. 3). The ADME profile was provided with radar that shown six predicted ADME parameters that are closely related to the oral bioavailability of a compound, including LIPO (lipophilicity), SIZE (size), POLAR (polarity), INSOLU (insolubility), INSATU (instauration), and FLEX (flexibility). The colored zone was a physical chemistry area that is suitable for oral bioavailability. Analysis of ADME profiles performed by radar showed Amphibine-B,
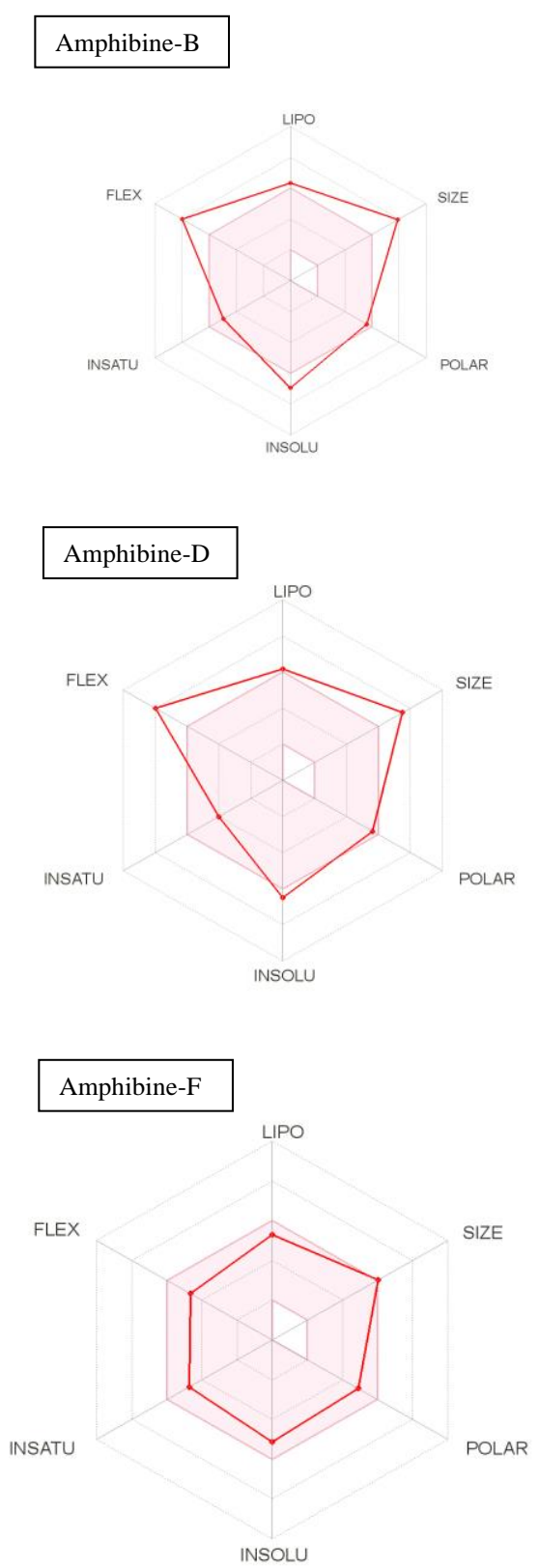

Amphibine-C, Amphibine-D, and Amphibine$F$ have suitable in polarity and insaturation following by oral drug bioavailability criteria, except for the lipophilicity, size, insolubility, and flexibility parameter. Amphibine-E compound radar is suitable for insaturation parameters. Amphibine-F compound radar shows a suitable in all parameters, i.e., lipophilicity, size, polarity, insolubility, insaturation, and flexibility. Amphibine-H compound radar shows a suitable in polarity, insolubility, insaturation, and lipophilicity criteria.

Amphibine-C
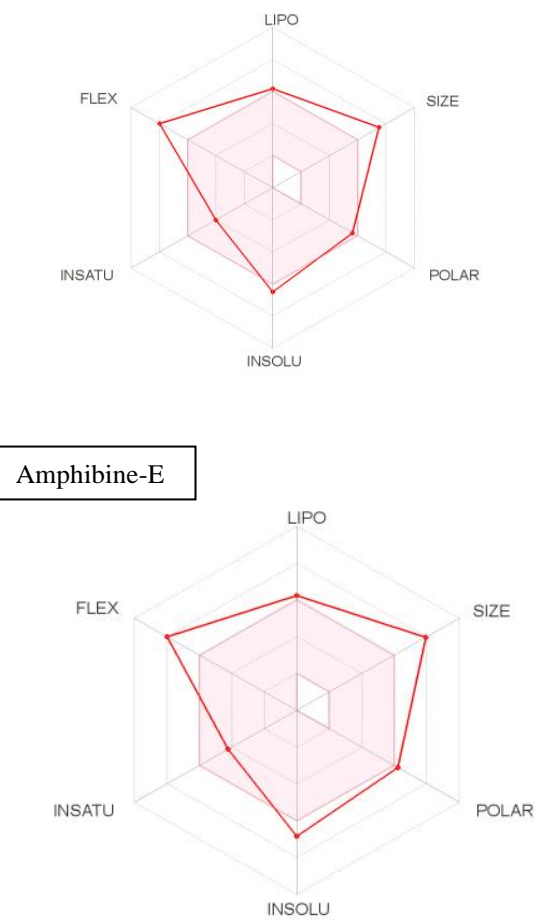

Amphibine-H

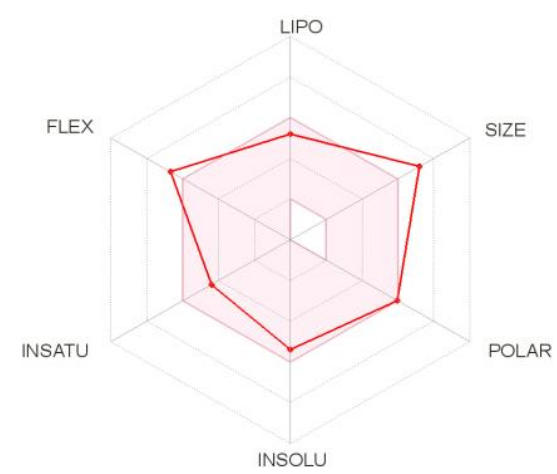

Fig. 3. Administration, distribution, metabolism, and elimination (ADME) parameters for amphibine B, C, D, E, F, and $\mathrm{H}$ that were evaluated by SWISS-ADME. 
Furthermore, lipinski analyses were performed to look for drug similarities or determine whether a chemical compound has specific pharmacological or biological activity has chemical and physical properties that make it pharmacokinetically effective in the human body, including ADME. In Lipinski druglikeness analysis, amphibine-B provided one violation (MW >500), amphibine-C provided one violation (MW >500), amphibine-D provided one violation ( $\mathrm{MW}>500$ ), amphibineE provided two violation (MW >500), and (NorO > 10), amphibine-F provided one violation (MW>500), Amphibine-H provided two violations $(\mathrm{MW}>500$, NorO $>10)$. The drug-likeness results showed amphibine-E and amphibine-H provided more than one violation, indicates poor bioavailability as oral drugs. Amphibine-B, C, D, and F showed one violation for drug-likeness criteria, indicates good bioavailability. In general, the amphibineF compounds showed the best bioavailability as an oral drug, amphibine-B, C, and D showed good bioavailability as an oral drug, and amphibine-E and $\mathrm{H}$ showed poor bioavailability as oral drugs.

\section{CONCLUSION}

The amphibine analogues from Ziziphus spina-christi species analyzed by biological activity, molecular docking, and ADME predictions were showed as potentially inhibitor candidates for the SARS-CoV-2 $\mathrm{M}^{\text {pro }}$ receptor. The biological activity prediction by PASS web server of amphibine analogues (AH) showed amphibine-B, C, D, E, F, and H have potential as antiviral and protease inhibitor agents. The molecular docking results of the amphibine-B, C, D, E, F, and $\mathrm{H}$ showed better binding affinity against SARS-CoV-2 $\mathrm{M}^{\text {pro }}$ compared to the native ligand as a reference inhibitor. These compounds also form interactions that are similar in some residues with the native ligand. The ADME prediction showed amphibine-F has the best bioavailability as an oral drug, amphibine-B, C, and $\mathrm{D}$ have good bioavailability as an oral drug from drug-likeness criteria, while amphibine-E and $\mathrm{H}$ show poor bioavailability as an oral drug. Concluded the Amphibine-B, C, D, E, F, and H have potential as a treatment of COVID-19 through inhibits the protease enzyme of SARSCoV-2 $\mathrm{M}^{\text {pro }}$, and some compounds can be formulated as oral administration (amphibineB, C, D, and F), and some in other administration (amphibine- $\mathrm{E}$ and $\mathrm{H}$ ).

\section{ACKNOWLEDGEMENTS}

The authors thank to the Department of Pharmacy, Faculty of Mathematics and Natural Sciences, Universitas Islam Bandung, for the research financially supported by the Independent Research Grant Program 2020, No. 03/PEN-PKM/I/2021.

\section{REFERENCES}

Ads EN, Rajendrasozhan S, Hassan SI, Sharawy SMS, Humaidi JR. 2017. Phytochemical, antimicrobial and cytotoxic evaluation of Ziziphus spina-christi (L.) stem bark. Biomedical Research. vol 28(15): 6646-6653.

Al-Ghamdi AA, Shahat AA. 2017. Antioxidant, hypoglycemic and anti-diabetic activities of Ziziphus spina-christi (L) Willd (Rhamnacae) leaf extract. Tropical Journal of Pharmaceutical Research. vol 16(11): 2601-2610. doi: https://doi.org/10.4314/tjpr.v16i11.5.

Alotibi FO, Ashour EH, Al-Basher G. 2020. Evaluation of the antifungal activity of Rumex vesicarius L. and Ziziphus spina-christi (L) Desf. Aqueous extracts and assessment of the morphological changes induced to certain myco-phytopathogens. Saudi Journal of Biological Sciences. vol 27(10): 28182828.

doi: https://doi.org/10.1016/j.sjbs.2020.06.051.

Anzali S, Barnickel G, Cezanne B, Krug M, Filimonov D, Poroikov V. 2001. Discriminating between drugs and nondrugs by prediction of activity spectra for substances (PASS). Journal of Medicinal Chemistry. vol 44(15): 2432-2437. doi: https://doi.org/10.1021/jm0010670.

Atilgan E, Hu J. 2011. Improving Protein Docking Using Sustainable Genetic Algorithms. International Journal of Computer Information Systems and Industrial Management Applications. vol 3(2011): 248-255.

Baghazadeh-Daryaii L, Sharifi-Sirchi GR, Samsampoor D. 2017. Morphological, phytochemical and genetic diversity of Ziziphus spina-Christi (L) Des. in South and Southeastern of Iran. Journal of Applied Research on Medicinal and Aromatic Plants. vol 7: 99-107. doi: https://doi.org/10.1016/j.jarmap.2017.06.006.

Bell EW, Zhang Y. 2019. DockRMSD: An open-source tool for atom mapping and RMSD calculation of symmetric molecules through graph isomorphism. Journal of Cheminformatics. vol 11(1): 1-9. doi: 
https://doi.org/10.1186/s13321-019-0362-7.

Benarba B, Pandiella A. 2020. Medicinal plants as sources of active molecules against COVID-19. Frontiers in Pharmacology. vol 11: 1-16. doi: https://doi.org/10.3389/fphar.2020.01189.

Calcagno N, Colombo E, Maranzano A, Pasquini J, Sarmiento IJK, Trogu F, Silani V. 2020. Rising evidence for neurological involvement in COVID19 pandemic. Neurological Sciences. vol 12: 1-3. doi: https://dx.doi.org/10.1007\%2Fs10072-02004447-w.

Chen D, Oezguen N, Urvil P, Ferguson C, Dann SM, Savidge TC. 2016. Regulation of protein-ligand binding affinity by hydrogen bond pairing. Science Advances. vol 2(3): 1-16. doi: https://doi.org/10.1126/sciadv.1501240.

Choudhury A, Mukherjee S. 2020. In silico studies on the comparative characterization of the interactions of SARS-CoV-2 spike glycoprotein with ACE-2 receptor homologs and human TLRs. Journal of Medical Virology. vol 92(10): 2105-2113. doi: https://doi.org/10.1002/jmv.25987.

Dai W, Zhang B, Jiang XM, Su H, Li J, Zhao Y, Xie X, Jin Z, Peng J, Liu F, Li C, Li Y, Bai F, Wang H, Cheng X, Cen X, Hu S, Yang X, Wang J, Liu X, Xiao G, Jiang H, Rao Z, Zhang LK, Xu Y, Yang H, Liu H. 2020. Structure-based design of antiviral drug candidates targeting the SARS-CoV-2 main protease. Science. vol 368(6497): 1331-1335. doi: https://doi.org/10.1126/science.abb4489.

Darusman F, Fakih TM. 2021. Comprehensive in silico analysis of christinin molecular behaviour from Ziziphus spina-christi leaves on Propionibacterium acnes. Pharmaceutical Sciences and Research. vol 8(1): 55-64. doi: https://doi.org/10.7454/psr.v8i1.1112.

Dias DA, Urban S, Roessner U. 2012. A historical overview of natural products in drug discovery. Metabolites. vol 2(2): 303-336. doi: https://doi.org/10.3390/metabo2020303.

Dong R, Pei S, Yin C, He RL, Yau SST. 2020. Analysis of the hosts and transmission paths of SARS-CoV2 in the COVID-19 outbreak. Genes. vol 11(6): 116. doi: https://doi.org/10.3390/genes11060637

El Maaiden E, El Kharrassi Y, Moustaid K, Essamadi AK, Nasser B. 2019. Comparative study of phytochemical profile between Ziziphus spina christi and Ziziphus lotus from Morocco. Journal of Food Measurement and Characterization. vol 13(1): 121-130. doi: https://doi.org/10.1007/s11694-018-9925-y.

Fakih TM, Ramadhan DSF, Darusman F. 2021. In silico activity identification of cyclo peptide alkaloids from Zizyphus spina-christi species against SarsCov-2 main protease. Jurnal Biodjati. vol 6(1): 7181. doi: https://doi.org/10.15575/biodjati.v6i1.10603.

Fu L, Ye F, Feng Y, Yu F, Wang Q, Wu Y, Zhao C, Sun H, Huang B, Niu P, Song H, Shi Y, Li X, Tan W, Qi J, Gao GF. 2020. Both Boceprevir and GC376 efficaciously inhibit SARS-CoV-2 by targeting its main protease. Nature Communications. vol 11(1): 1-8. doi: https://doi.org/10.1038/s41467-02018233-X.

Gentile D, Patamia V, Scala A, Sciortino MT, Piperno A, Rescifina A. 2020. Putative inhibitors of SARSCOV-2 main protease from a library of marine natural products: A virtual screening and molecular modeling study. Marine Drugs. vol 18(4): 1-16. doi: https://doi.org/10.3390/md18040225.

Giannozzi P, Baseggio O, Bonfâ P, Brunato D, Car R, Carnimeo I, Cavazzoni C, De Gironcoli S, Delugas P, Ruffino FF, Ferretti A, Marzari N, Timrov I, Urru A, Baroni S. 2020. Quantum ESPRESSO toward the exascale. Journal of Chemical Physics. vol 152(15): 1-11. doi: https://doi.org/10.1063/5.0005082.

Gorai M, Romdhane R, Maraghni M, Neffati M. 2019. Relationship between leaf gas-exchange characteristics and the performance of Ziziphus spina-christi (L.) Willd. seedlings subjected to salt stress. Photosynthetica. vol 57(3): 897-903. doi: https://doi.org/10.32615/ps.2019.093.

Goyal B, Goyal D. 2020. Targeting the dimerization of the main protease of coronaviruses: a potential broad-spectrum therapeutic strategy. ACS Combinatorial Science. vol 22(6): 297-305. doi: https://doi.org/10.1021/acscombsci.0c00058.

Griffin JW. 2020. SARS-CoV and SARS-CoV-2 main protease residue interaction networks change when bound to inhibitor N3. Journal of Structural Biology. vol 211(3): 1-9. doi: https://doi.org/10.1016/j.jsb.2020.107575.

Han Y, Král P. 2020. Computational design of ACE2based peptide inhibitors of SARS-CoV-2. ACS Nano. vol 14(4): 5143-5147. doi: https://doi.org/10.1021/acsnano.0c02857.

Harvey AL, Edrada-Ebel R, Quinn RJ. 2015. The reemergence of natural products for drug discovery in the genomics era. Nature Reviews Drug Discovery. vol 14(2): 111-129. doi: https://doi.org/10.1038/nrd4510.

Jin Z, Du X, Xu Y, Deng Y, Liu M, Zhao Y, Zhang B, Li X, Zhang L, Peng C, Duan Y, Yu J, Wang L, Yang K, Liu F, Jiang R, Yang X, You T, Liu X, Yang X, Bai F, Liu H, Liu X, Guddat LW, Xu W, Xiao G, Qin C, Shi Z, Jiang H, Rao Z, Yang H. 2020. Structure of Mpro from SARS-CoV-2 and discovery of its inhibitors. Nature. vol 582(7811): 289-293. doi: https://doi.org/10.1038/s41586-0202223-y.

Kalayou S, Haileselassie M, Gebre-egziabher G, Tiku'e T, Sahle S, Taddele H, Ghezu M. 2012. In-vitro antimicrobial activity screening of some ethnoveterinary medicinal plants traditionally used against mastitis, wound and gastrointestinal tract complication in Tigray Region, Ethiopia. Asian Pacific Journal of Tropical Biomedicine. vol 2(7): 516-522. doi: https://doi.org/10.1016/S22211691(12)60088-4. 
Khaerunnisa S, Kurniawan H, Awaluddin R, Suhartati S, Soetjipto S. 2020. Potential inhibitor of COVID-19 main protease (Mpro) from several medicinal plant compounds by molecular docking study. Preprints. vol 2020: 1-14. doi: https://doi.org/10.20944/preprints202003.0226.v1.

Kwape TE, Chaturvedi P, Kamau JM, George S. 2013. Hepato-protective potential of methanol extract of leaf of Ziziphus mucronata (ZMLM) against dimethoate toxicity: biochemical and histological approach. Ghana Medical Journal. vol 47(3): 112120.

Lagunin A, Stepanchikova A, Filimonov D, Poroikov V. 2000. PASS: Prediction of activity spectra for biologically active substances. Bioinformatics. vol 16(8): 747-748. doi: https://doi.org/10.1093/bioinformatics/16.8.747.

Lakshmi SA, Shafreen RMB, Priya A, Shunmugiah KP. 2020. Ethnomedicines of Indian origin for combating COVID-19 infection by hampering the viral replication: using structure-based drug discovery approach. Journal of Biomolecular Structure and Dynamics. vol 39(13): 4594-4609. doi: https://doi.org/10.1080/07391102.2020.1778537.

Ma C, Sacco MD, Hurst B, Townsend JA, Hu Y, Szeto T, Zhang X, Tarbet B, Marty MT, Chen Y, Wang J. 2020. Boceprevir, GC-376, and calpain inhibitors II, XII inhibit SARS-CoV-2 viral replication by targeting the viral main protease. Cell Research. vol 30(8): 678-692. doi: https://doi.org/10.1038/s41422-020-0356-z.

Mahanthesh MT, Ranjith D, Yaligar R, Jyothi R, Narappa G, Ravi MV. 2020. Swiss ADME prediction of phytochemicals present in Butea monosperma (Lam.) Taub. Journal of Pharmacognosy and Phytochemistry. vol 9(3): 1799-1809.

Maiti BK. 2020. Potential role of peptide-based antiviral therapy against SARS-CoV-2 infection. ACS Pharmacology \& Translational Science. vol 3(4): 783-785.

doi: https://doi.org/10.1021/acsptsci.0c00081.

Mirza MU, Froeyen M. 2020. Structural elucidation of SARS-CoV-2 vital proteins: Computational methods reveal potential drug candidates against main protease, Nsp12 polymerase and Nsp13 helicase. Journal of Pharmaceutical Analysis. vol 10(4): 320-328. doi: https://doi.org/10.1016/j.jpha.2020.04.008.

Moossavi M, Hoshyar R, Hemmati M, Farahi A, Javdani H. 2017. An invivo study on the hepato-protective effects of Crocus sativus, Ziziphus jujuba and Berberis vulgaris against acute acetaminophen and rifampicin-induced hepatotoxicity. Clinical Phytoscience. vol 2(1): 1-7. doi: https://doi.org/10.1186/s40816-016-0030-7.

Murdocca M, Citro G, Romeo I, Lupia A, Miersch S, Amadio B, Bonomo A, Rossi A, Sidhu SS, Pandolfi PP, Alcaro S, Sangiuolo FC, Novelli G. 2021. Peptide platform as a powerful tool in the fight against COVID-19. Viruses. vol 13(8): 1-21. doi: https://doi.org/10.3390/v13081667

Reiner Ž, Hatamipour M, Banach M, Pirro M, Al-Rasadi K, Jamialahmadi T, Radenkovic D, Montecucco F, Sahebkar A. 2020. Statins and the Covid-19 main protease: In silico evidence on direct interaction. Archives of Medical Science. vol 16(3): 490-496. doi: https://dx.doi.org/10.5114\%2Faoms.2020.94655.

Sakna ST, Mocan A, Sultani HN, El-Fiky NM, Wessjohann LA, Farag MA. 2019. Metabolites profiling of Ziziphus leaf taxa via UHPLC/PDA/ESI-MS in relation to their biological activities. Food Chemistry. vol 293: 233-246. doi: https://doi.org/10.1016/j.foodchem.2019.04.097.

Tanbin S, Fuad FAA, Hamid AAA. 2021. Virtual screening for potential inhibitors of human hexokinase II for the development of anti-dengue therapeutics. Biotech. vol 10(1): 1-28. doi: https://doi.org/10.3390/biotech10010001.

Thompson RN. 2020. Novel coronavirus outbreak in Wuhan, China, 2020: intense surveillance is vital for preventing sustained transmission in new locations. Journal of Clinical Medicine. vol 9(2): 17. doi: https://doi.org/10.3390/jcm9020498.

WHO. 2021. Weekly operational update on COVID-191 March 2021. Geneva: World Health Organization. https://www.who.int.

Zhu H, Wei L, Niu P. 2020. The novel coronavirus outbreak in Wuhan, China. Global Health Research and Policy. vol 5(1): 1-3. doi: https://doi.org/10.1186/s41256-020-00135-6. 